\title{
Convolvulus arvensis, a new host for Alternaria solani causing early blight of Solanum lycopersicum in Pakistan
}

\author{
K. P. Akhtar • N. Sarwar • M. Y. Saleem • M. Asghar
}

Received: 22 June 2011 / Accepted: 22 September 2011 /Published online: 1 October 2011

(C) Australasian Plant Pathology Society Inc. 2011

\begin{abstract}
In March-April 2011, a severe outbreak of early blight disease caused by Alternaria solani was observed on Solanum lycopersicum (cultivated tomatoes) at the Nuclear Institute for Agriculture and Biology (NIAB), Faisalabad, Pakistan. A similar type of symptoms was also observed on Convolvulus arvensis (field bindweed, lehli). Based on disease symptoms, morphological characteristics and pathogenicity test, it has been confirmed that the $A$. solani could infect $C$. arvensis. To the best of our knowledge this is the first report of A. solani infecting $C$. arvensis in Pakistan.
\end{abstract}

Keywords Alternaria solani Convolvulus arvensis · early blight $\cdot$ Solanum lycopersicum

Early blight caused by Alternaria solani is one of the most common and destructive diseases of S. lycopersicum (cultivated tomatoes) in the tropical and subtropical regions of the world (Foolad et al. 2008). During March-April 2011 a severe outbreak of early blight was observed at the Nuclear Institute for Agriculture and Biology (NIAB), Faisalabad, Pakistan with disease incidence of $10-100 \%$ and yield losses from 20 to $80 \%$. A similar type of symptoms was also observed on $C$. arvensis (field bindweed, lehli). C. arvensis is a destructive perennial weed and a problem in many annual and perennial crops, which trails over the ground and climbs among the crops

K. P. Akhtar $(\bowtie) \cdot$ N. Sarwar $\cdot$ M. Y. Saleem • M. Asghar

Nuclear Institute for Agriculture and Biology,

Faisalabad, Pakistan

e-mail: kpervaiz_mbd@yahoo.com pulling them down and hindering harvesting (Weaver and Riley 1982; Pfirter et al. 1997). Disease symptoms on $C$. arvensis were started as small dark, necrotic lesions usually on the older leaves. At later stage, lesions commonly have concentric rings with a target-like appearance, often surrounded by a yellow zone and when spotting was abundant the entire leaf turns yellow (Fig. 1).

A total of 15 symptomatic leaf samples from $C$. arvensis were collected. These samples were cut into small pieces $(5 \mathrm{~mm})$ and disinfected in $1 \%$ solution of sodium hypochlorite $(\mathrm{NaOCl})$ for $1 \mathrm{~min}$., then rinsed twice with sterile distilled water, plated on to moistened filter papers in glass Petri plates and incubated at $25^{\circ} \mathrm{C}$. After 2-3 days of incubation grey colonies emerged from the symptomatic tissues. Conidiophores of the fungus were straight or flexuous, septate, dark in colour, thick and arising singly or in small groups. Conidia were beaked, usually solitary, straight or slightly flexuous, obclavate or with the body of the conidium oblong or ellipsoidal tapering to a beak. The beak is commonly the same length as or rather longer than the body (some time branched), dark brown, smooth with 9-11 transverse and 0 to a few longitudinal or oblique septa (Fig. 2a, b). Based on the symptoms, cultural, mycelial and conidial characteristics, the isolated pathogen was identified as A. solani (Ellis 1971; Ellis and Gibson 1975).

To perform a pathogenicity test, $A$. solani was grown on V8 medium (17.7\% V8 juice, $0.3 \% \mathrm{CACO}_{3}, 2 \%$ agar) at 21 to $23^{\circ} \mathrm{C}$ under a cool-white florescent diurnal light with a $12 \mathrm{~h}$ dark and light cycle. After 10 to 14 days, conidia were harvested by applying sterilized deionized water (containing $0.01 \%$ Tween 20 ) and gently scraping the culture surface with a microscopic glass slide. The conidial suspension was filtered through a $0.5-\mathrm{mm}^{2}$-pore strainer 


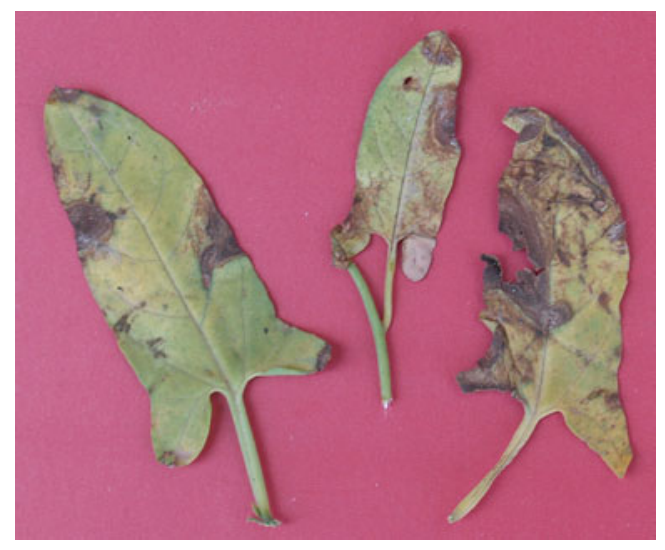

Fig. 1 Dark, necrotic lesions, having concentric rings surrounded by a yellow zone on the older leaves of $C$. arvensis

to remove mycelia debris. The resulting spore suspension was adjusted to 2000 conida per $\mathrm{ml}$ using a haemocytometer (Foolad et al. 2000).

Koch's postulate were fulfilled using the detached leaf assay (Foolad et al. 2000). Fully expanded leaves were detached from the middle of the $C$. arvensis and $S$. lycopersicum (variety; Nagina) plants at the base of the petiole. Leaves were placed adaxial side up on moistened filter paper in glass Petri dishes (140 mm dia.) and each leaf was inoculated with a $50 \mu \mathrm{l}$ drop of conidial suspension at the centre of the adaxial surface. The experiment was replicated ten times and the inoculated leaves were incubated in the dark for $24 \mathrm{~h}$ at $\sim 22^{\circ} \mathrm{C}$ then placed under a cool-white florescent diurnal light with a $12 \mathrm{~h}$ photoperiod. The detached leaves were examined $72 \mathrm{~h}$ after inoculation and then for 7 days post inoculation. All the

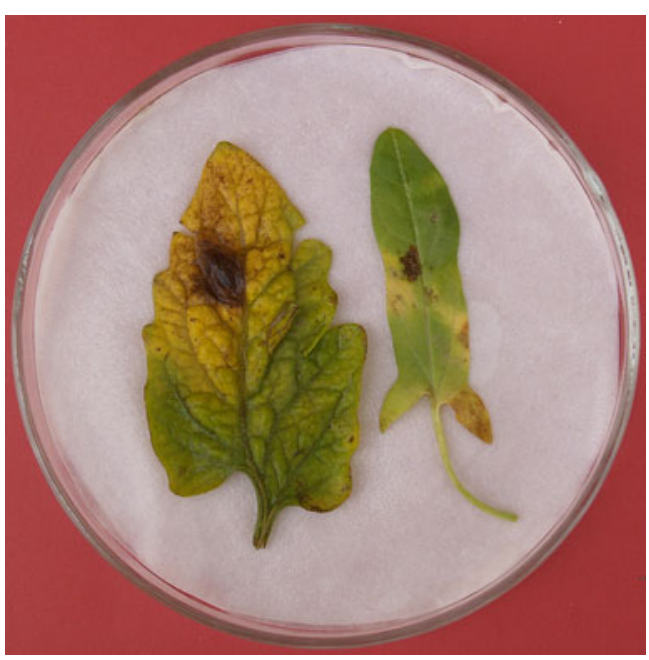

Fig. 3 Detached leaf inoculation with A. solani isolated from $C$. arvensis. Note the dark, necrotic lesions on C. arvensis leaf (on right) and dark, necrotic lesions with concentric rings surrounded by a yellow zone on $S$. lycopersicum leaf (on left)

inoculated leaves of $C$. arvensis and S. lycopersicum produced symptoms after 3 days. Severe symptoms similar to those observed in the field were observed after 5-7 days (Fig. 3) and A. solani was consistently re-isolated from these leaves.

A. solani has previously been reported as a pathogen of S. lycopersicum and other plants belonging to the Solanaceae such as potato ( $S$. tuberosum L.), eggplant $(S$. melongena L.), horsenettle (S. carolinense L.) and black nightshade (S. nigrum L.) (Ellis 1971; Jones et al. 1997). To the best of our knowledge this is the first report of $A$. solani infecting $C$. arvensis.
Fig. 2 Alternaria solani (a-b). a Conidium with long beak. b Conidium with branched beaks
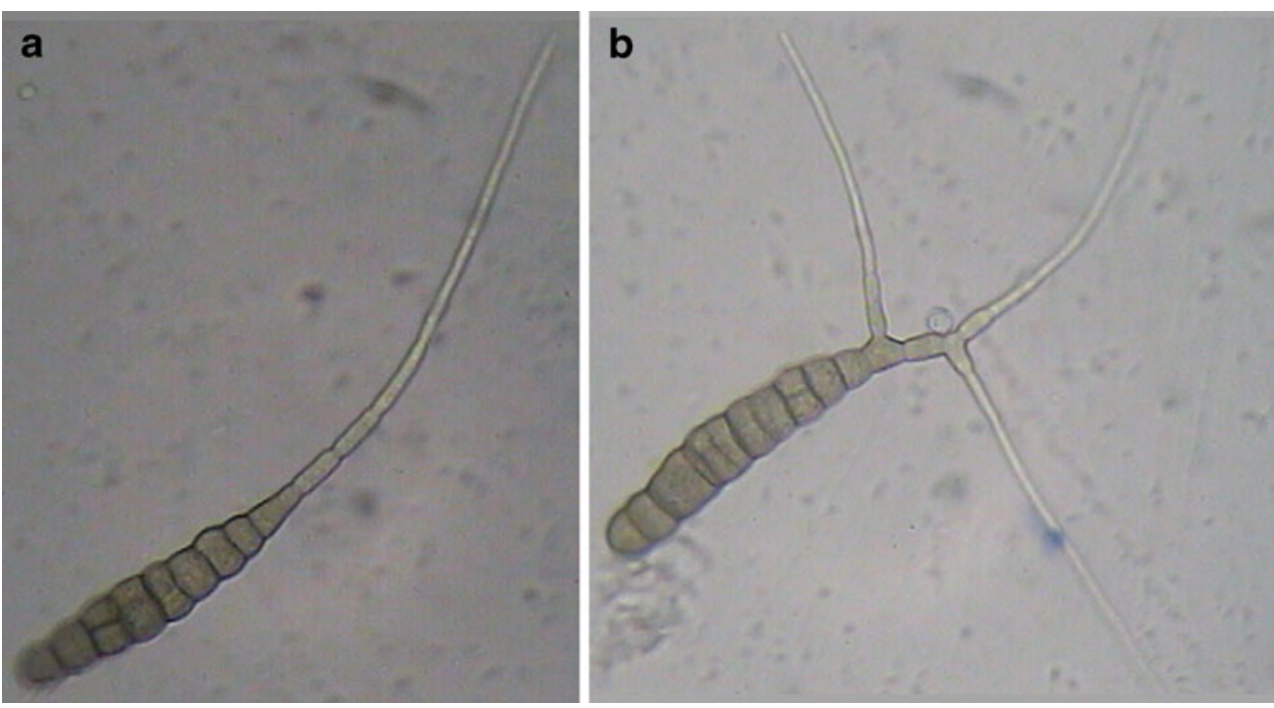
Acknowledgements The authors are thankful to Dr Akhlaq Hussain, Project Director, for providing V8 medium to conduct this study under the project entitled "Establishment of facilitation unit for participatory vegetable seed and nursery production programme" funded by MINFA, Islamabad. We are also thankful to Dr Q. Iqbal and Mr. K. Saleem, NIAB, for their useful assistance.

\section{References}

Ellis MB (1971) Dematiacceous Hyphomycetes. Commonwealth Mycological Institute, Kew

Ellis MB, Gibson IAS (1975) Alternaria solani. CMI Descriptions of pathogenic fungi and bacteria. No. 475. Commonwealth Mycological Institute, Kew
Foolad MR, Ntahimpera N, Christ BJ, Lin GY (2000) Comparison of field, green house, and detached-leaflet evaluation of tomato germplasm for early blight resistance. Plant Dis 84:967-972

Foolad MR, Merk HL, Ashrafi H (2008) Genetics, genomics and breeding of late blight and early blight resistance in tomato. Crit Rev Plant Sci 27:75-107

Jones JB, Jones JP, Stall RE, Zitter TA (1997) Compendium of tomato diseases. The American Phytopathological Society. 3340. Pilot Knob Road, Minnesota, 55121-2097, U SA. 73p

Pfirter HA, Ammon HU, Guntli D, Greaves MP, Defago G (1997) Towards the management of field bindweed (Convolvulus arvensis) and hedge bindweed (Calystegia sepium) with fungal pathogens and cover crops. Integrated Pest Manag Rev 2:61-69

Weaver SE, Riley WR (1982) The biology of Canadian weeds. 53. Convolvulus arvensis. Can J Plant Sci 62:461-72 